\title{
8. PERFORMANCE OF THE WATER-SAMPLER TEMPERATURE PROBE COLLETED DELIVERY TOOL ON LEG 124E SEA TRIALS1
}

\author{
Thomas L. Pettigrew ${ }^{2}$
}

\section{INTRODUCTION}

The water-sampler temperature probe (WSTP) colleted delivery tool was designed to aid the delivery of the probe to bottom. This tool enables the probe to be delivered on wireline to minimize damage to the internal electronic circuitry. With the drillstring bottom-hole assembly (BHA) off bottom, and the colleted delivery tool latched in, the probe is allowed to extend past the face of the bit $14 \mathrm{ft}, 0.375 \mathrm{in}$. When the BHA is lowered and the probe contacts bottom, the probe will retract inside the BHA until it extends 42 in. beyond the bit face. At that point the load collets contact, and the load will be applied to the probe to drive it into the formation. If the load on the probe exceeds $11,000 \mathrm{lb}$, the collets release, allowing the probe to retract completely inside the BHA. The collets can be reset simply by picking up the drill string and allowing the weight of the colleted delivery tool to restroke itself. Once the probe has been driven into the formation, the tool allows the BHA to be picked up off bottom, taking the weight off the formation while decoupling the probe from the ship's heave motion.

The significant change to the tool that required testing was the increase of the decoupling/heave stroke from 11 to $22 \mathrm{ft}$. That change necessitated using a small-diameter (1 1/4-in.) rod as one of the stroking members. The pull strength was reduced

\footnotetext{
${ }^{1}$ Harding, B. W., Storms, M. A., et al., 1990. Proc. ODP, Init. Repts., 124E: College Station, TX (Ocean Drilling Program).

2 Shipboard engineering and scientific parties are as given in the listing of participants preceding the contents.
}

from 100,000 to $35,000 \mathrm{lb}$. However, since the maximum load driving the probe into the formation is $11,000 \mathrm{lb}$, the reduced pull strength is not a problem. The main concern was rig-floor handling. The handling problems are minimized by the ability to lock the tool in the unstroked position during handling.

\section{SEA TRIALS}

Initial shipboard preparations involved disassembling the existing tool and reassembling it with the new parts. A dummy probe was made up and installed on the tool.

The tool was deployed at Site 772. Although the tool is not intended to be free-fall deployed, for a worst case test, the tool was free-fall deployed with no apparent adverse effect. The standard wireline sinker-bar assembly was deployed to retrieve the tool. Once the tool was at the rig floor, it was telescoped closed and locked. The tool then was removed from the drill pipe and placed in a storage shuck for future use.

\section{CONCLUSIONS}

The tool was deployed only once on Leg $124 \mathrm{E}$, and it will need to be handled and run several more times for a full evaluation. However, the main concern was rig-floor handling; as no problems were evident, the tool should continue to be deployed in normal operations and should be evaluated further.

\section{RECOMMENDATIONS}

The tool posed no additional rig-floor operational problems and should be used for normal WSTP deployments. Further data should be gathered as the tool is fully evaluated.

Ms 124E-108 